
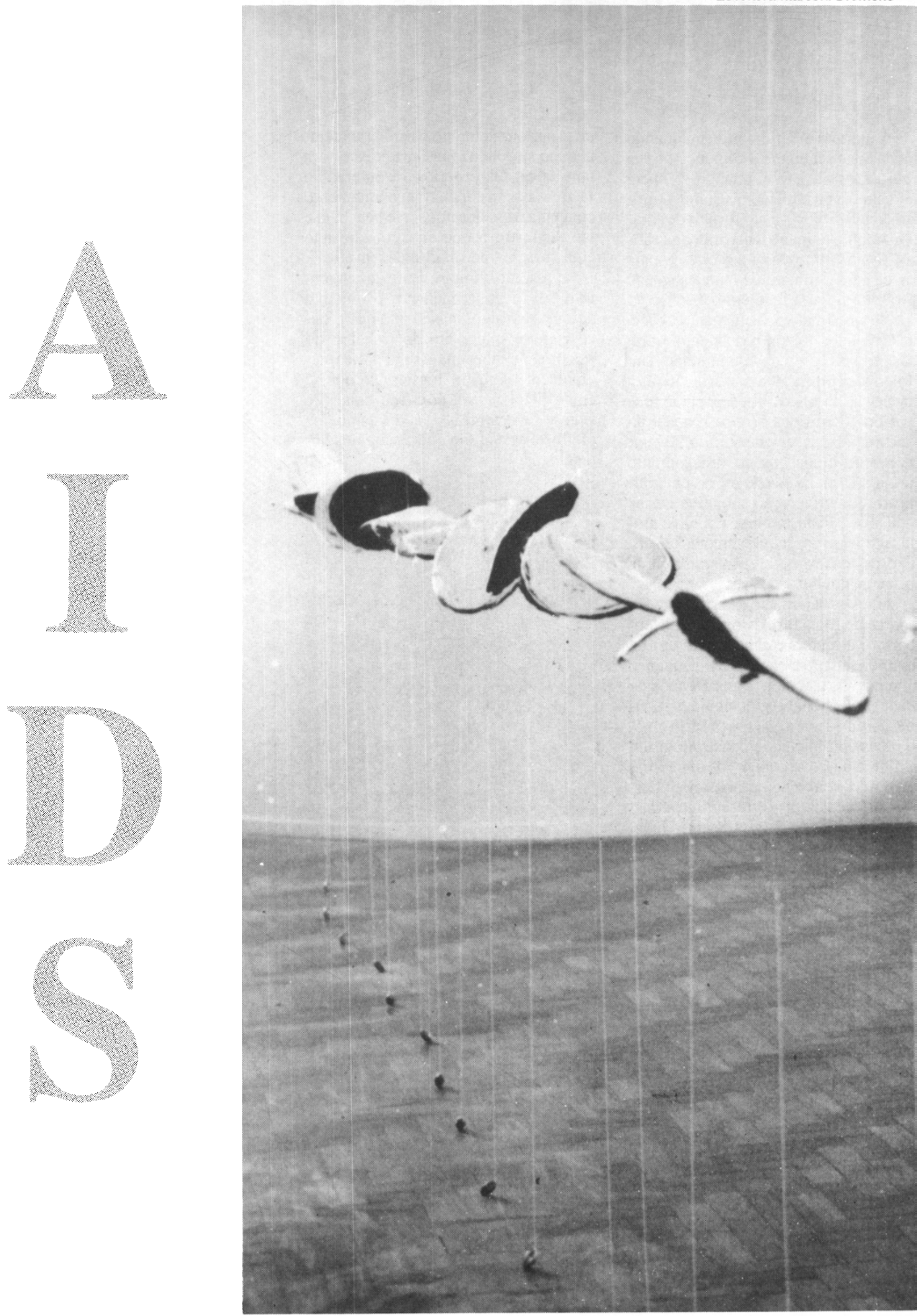


\section{Quem ganha com a discriminação e a desinformação}

\author{
Luíza Alonso * \\ $\left(^{*}\right)$ Professora no Departamento de Psicologia \\ Social e do Trabalho - IPSUSP
}

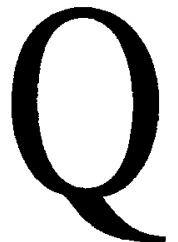

uando vivemos em um contexto social onde as questões éticas do dia a dia são regidas pela máxima "levar vantagem em tudo", falar em democratizar informações é em um grande número de casos passar atestado de ingenuidade para si mesmo.

Estamos tão acostumados a esconder informações uns dos outros que isso até parece ser um comportamento normal. E se o conceito de normal for tão somente o número de incidências, é realmente normal. Afinal a informação é nos dias de hoje, mais do que nunca, uma preciosa mercadoria carregada de representações sociais.

No entanto, não é qualquer informação que tem esse valor, mas apenas aquelas com as quais podemos obter algum benefício, ou na Lei de Gérson, levar alguma vantagem. É comum, por exemplo, algumas pessoas esconderem informações sobre serviços que deveriam atingir a todos, com medo de que se todos souberem, o benefício vai acabar, e aí elas vão ficar sem. Ou então darem informaçōes pela metade, ajudando na confusão (e.g. informar erroneamente sobre a localizaçãode um posto de atendimento do INAMPS).

Mas por que tudo isso ocorre?

Certamente se pensarmos em Gramsci sobre o seu conceito de hegemonia, vamospoder entender esse processo onde um valor traduzido em atitudes e comportamentos de uma elite econômica e política, passa a fazer parte do dia a dia de toda uma população sem distinções de classe. Historicamente no Brasil, a elite sempre se manteve à custa da ignorância ou desinformação, e da miséria do povo brasileiro. Vide as últimas eleições presidenciais quando os descamisados, descalços, desnutridos, des-aquilos e des-tudo, votaram no que tem muitas camisas, muitos sapatos, muita comida, mas nenhum programa efetivo com relação à situação econômica e social da maioria dos brasileiros, e que não tem sequer um plano que garanta à maioria o acesso aos serviços de saúde e educação.

Eu me lembro bem dos anos 70 , quando junto com vários companheiros militantes, fomos trabalhar na periferia e ouvíamos particularmente dos agentes religiosos o quão maravilhoso e sublime era trabalhar com o povo pobre, que no seu entender era 0 possuidor da Verdade. Era tudo tão simples, bastava ser pobre e lascado para ter a Sabedoria e ser Solidário. Feliz ou infelizmente nem sempre isso ocorreu, e a solidariedade, essa prática tão distante dos pequenos burgueses e tão utópica neste mundo capitalista, algumas vezes se mostrou madrasta. Era-se solidário até ter o seu problema pessoal resolvido.

Contudo, hoje a questão da Solidariedade volta à cena. $E$ volta porque a sociedade enquanto um todo precisa reinventar as suas práticas. Não é vida viver trancado dentro de casa, desconfiando de todos, cheio de medos e preconceitos. Hoje as questões de justiça, igualdade sócio-política, distribuição de renda e cidadania imperam como necessidades básicas. A sociedade precisa se organizar para fazer valer os seus direitos e ter os seus interesses respeitados. Não a sociedade utópica e sem conflitos que alguns livros de História nos tentaram enfiar goela abaixo. Massociedade dos trabalhadores, dos que produzem, dos que fazem.

Neste contexto o fenômeno AIDS é um dos expoentes onde as ansiedades, expectativas, conflitos ecisōes ideológicas aparecem de forma cristalina. AIDS não é um problema de um grupo ou de um sub-grupo como nos querem fazer crer. AIDS também não é punição ou castigo. AIDS é mais que um problema de saúde, é um assunto para políticos, teólogos, filósofos, sociólogos, médicos, para todos os especialistas e principalmente para todos os não-especialistas, enfim para todos os cidadãos, porque diz respeito a todos nós, porque mexe direta ou indeiretamente com tudo o que considerávamos certo ou errado, com nossascrenças, valores, idéias, imagens, enfim porque diz respeito ao direito à vida civil, profissional, sexual e afetiva de todos nós, quer a gente queira ou não, quer a gente goste ou não. 
Quando se luta para que os pacientes de AIDS recebam um tratamento digno e honesto, essa é uma luta de todos os que precisam ou não dos serviços médicos garantidos não por Lei, mas pelo desconto mensal de todos os que trabalham neste país.

Quando empreendemos uma luta para que os pacientes e portadores de AIDS não sofram discriminações, estamos falando de todos aqueles que já perderam uma promoção porque são mulheres, dos que não conseguem mais arrumar um emprego porque têm mais de 40 anos de idade, daqueles que não passaram na seleção por causa do jeito meio-esquisito ou porque não tinham a tal da boa aparência, enfim daqueles que por conta de raça, idade, gênero, religião, orientação sexual, por serem portadores de doenças crônicas, nivel socio-econômico, posição política, foram rejeitados e atirados, ainda que uma só vez, na lixeira dos inapropriados e/ou inadequados.

Só que se isso em alguns lugares é algo que concerne a uma minoria, no Brasil diz respeito a uma maioria; estamos todos num grande e imenso barcocargueiro. Aqui são muitos os que precisam lutar para serem aceitos e não estigmatizados; para receberem ajuda e solidariedade de profissionais de saúde e de educação, de religiosos, de parentes e amigos; para poderem expressar suas emoçðes sem serem julgados por suas opções e práticas; e para serem respeitados e terem preservados seus direitos enquanto cidadãos.

A elite olha para nós com desprezoe desdém. Somos os infelizes, os coitadinhos, e se ousamos reclamar, os chatos, os comunistas, os desocupados, os malresolvidos e os mal-amados. Afinal reclamar prá que? Você não tem nenhum conhecido que possa resolver o seu problema? Você não tem jogo de cintura? Não sabe criar contactos?

E reproduzimos entre nós a mesma atitude que a elite tem conosco. A solidariedade é para os momentos especiais, para as grandes comemoraçōes e ou celebrações. No cotidiano, sabe comoé, né, a gente faz o que pode. $E$ vamos empurrando com a barriga a correria do dia a dia, da vidinha cinzenta e fria, do pagar as contas do mês, do viver sem dinheiro, da cultura do oi tudo bem? Tudo bem, e aí, tudo bem? Tudo. E apressamos o passo para que não vejam o arremedo de sorriso transformar 0 nosso rosto em uma caricatura de nós mesmos.

A nível psico-social muito da AIDS não se conhece. A palavra AIDS traz medo ao coração de quem a escuta. Muitos dos tópicos que ofenômeno AIDS traz são novos e balançam velhas convicōes sobre valores e prioridade, o que produz no mínimo desconforto e confusão.

Ainda conhecemos pouco sobre:

- como a doença se enquadra dentro do estilo de vida do sujeito?

- como o portador e ou paciente convive com o novo diagnóstico? Como vivia antes?

- qual é o stress causado pelo diagnóstico? Como isso é vivido no cotidiano?

- qual é a qualidade do relacionamento afetivo entre os pacientes e ou portadores com aqueles com quem convive?

- quais são as mudanças nos padrōes de relacionamento durante o curso da doença?

- quais são as oportunidades para expressar raiva, culpa, vergonha, medo, impotência, mágoa, frustrações e sentimentos? Quem escuta essas pessoas?

Quem nos escuta?

A AIDS afeta hemofílicos, usuários de drogas, recém-nascidos e pessoas de diferentes orientações sexuais, ou seja: Todos nós, Alguns desses grupos historicamente já experimentam a opressão e a rejeição de nossa sociedade por séculos, caracterizado por exemplo, pela alienação da família e por muitas e muitas perdas na vida. Mas como já dissemos antes os grupos minoritários que são alienados e desrespeitados no Brasil compõem a maioria da nossa população. Assim, se pensarmos a AIDS enquanto um castigo, ou uma punição, temos que pensar que é um castigo por não termos votado nos melhores representantes políticos, por não termos organizações estruturadas o suficiente para efetivamente intervirmos noplanejamento e na aplicação de políticas públicas que atendam os interesses e as necessidades de todos nós; por não termos conseguido até o momento mobilizar toda a sociedade para a defesa de seus interesses.

Uma última questão, evitando ser demagoga, piegas, ou Poliana, e sem desmerecer, diminuir ou esquecer a dor que acompanha a AIDS, até que ponto o fenômeno AIDS nãoé uma oportunidade para avaliar a qualidade de vida de todos nós e determinar o que é importante e o que é insignificante na vida, para desenvolvermos a amizade e a solidariedade, e para termos entre nós um compromisso afetivo de construção Nossa e do Mundo em que vivemos?

Este texto foi apresentado no I Encontro Aids - Repercussöes Psicossociais, em 10.09.1991, na USP

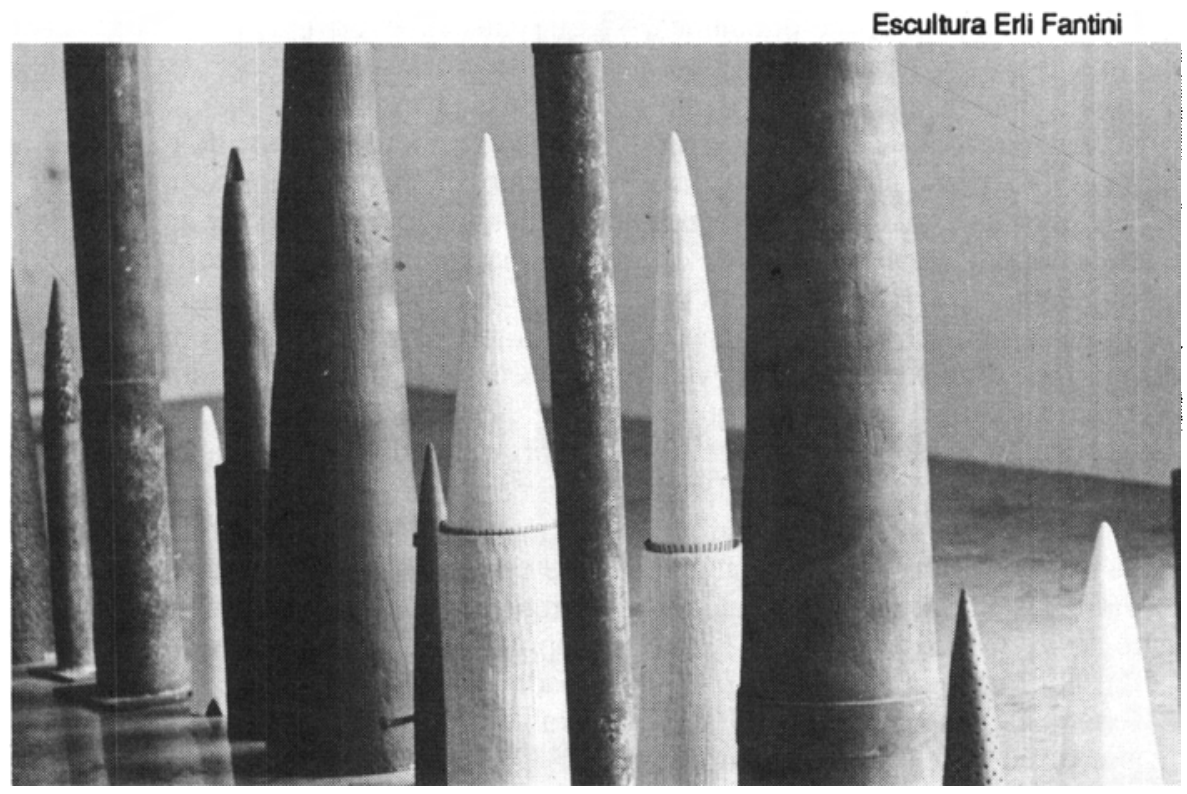

